\title{
Os espiões de Minerva
}

\section{MATHEUS CARDOSO DA SILVA I}

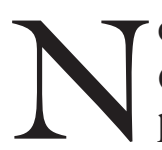

O MOMENTO em que os trabalhos da Comissão Nacional da Verdade, das Comissões estaduais e as Comissões da Verdade Universitárias se consolidam e trazem para a esfera pública os debates em torno da reconstrução da memória coletiva daqueles que sofreram perseguições políticas e ideológicas nos anos de autoritarismo entre 1964 e 1985 e na busca pela verdade e justiça contra os crimes de Estado cometidos naquele período, o presente trabalho do historiador Rodrigo Patto Sá Motta, professor titular do Departamento de História da Universidade Federal de Minas Gerais, constitui-se em obra da mais alta relevância para o cenário político brasileiro atual.

Como ponto-chave de sua pesquisa está a demonstração de toda a ambiguidade por trás das políticas autoritárias do Estado militar brasileiro no período ditatorial. Com isso, ele se estrutura em dois grandes eixos de análise. De um lado, o que se considerou chamar de "impulso modernizador" das políticas da ditadura, calcadas em projetos de transformação macroeconômica da sociedade e da industria brasileira que, em muitos aspectos, visava dar continuidade ao impulso modernizador da década anterior (1950) e das transformações do nacional-desenvolvimentismo do governo de Juscelino Kubitschek. O reflexo para o ensino superior nacional foi a reforma da universidade brasileira, iniciada em 1968. De outro, estava a face conservadora da ditadura militar brasileira, que deu o tom "destrutivo", nas palavras de Motta, para esse processo de modernização, inclusive do ensino superior nacional. A ditadura prendeu, demitiu ou aposentou compulsoriamente qualquer docente acusado de atividades ilegais ou de práticas "subversivas" dentro das universidades, públicas e privadas. Além disso, torturou e matou outros membros das comunidades acadêmicas, cujo papel ou representatividade política fosse considerado perigoso ao Estado, além da censura instaurada dentro das universidades, inviabilizando publicações, pesquisas e viagens ao exterior, assim como a vinda de estrangeiros ao Brasil.

A repressão será tema dos capítulos 1, 4 e 5, do presente trabalho. No primeiro capitulo, o foco será o expurgo desencadeado pelos militares dentro das universidades logo após o golpe, em $1^{\circ}$ de abril de 1964 , cuja alça de mira estava sobre aqueles considerados "comunistas". Tratado como o projeto central da ditadura militar (Motta, 2002), a caça aos comunistas se seguiu dentro dos sindicatos, das organizações de trabalhadores rurais e nas instituições universitárias, estas últimas tidas como espaço não apenas de manifestação de ideias políticas de esquerda, mas como centro de formação dos quadros militantes dos grupos de resistência ao $\operatorname{regime}^{\mathrm{l}}$ (p.25). 
O capítulo 4 tratará do período posterior à decretação do Ato Institucional número 5 (AI-5), em 13 de dezembro de 1968, quando ocorreu a segunda onda de limpeza para completar aquilo que havia começado em 1964. Com o AI-5, uma série de comissões foi criada para investigar os chamados "crimes políticos”, como a Comissão de Investigação Sumária do MEC (Cismec), que daria suporte à cassação de funcionários militares e civis em suas áreas ministeriais. A coordenação desses órgãos seria feita pela Comissão Geral de Inquérito Policial-Parlamentar (p.154).

Outro instrumento criado para dar poderes legais para as ações de punição política e ideológica foi o Decreto n.477, promulgado em fevereiro de 1969, cujo objetivo era coibir o ativismo estudantil, fresco na memória dos militares desde os eventos de 1968. Segundo o projeto "Brasil Nunca Mais", 2 foi punido um total de 245 estudantes em dez anos de vigência do Decreto. Esse número é relativamente baixo, se considerado ao mesmo tempo a "celebridade" do Decreto n.477 e o número de estudantes universitários regularmente matriculados à época: em 1969, ano em que o Decreto entrou em vigor, havia cerca de 350 mil estudantes universitários, e em 1973, mais de 700 mil. Motta lembra ainda que o total de estudantes excluídos pela repressão passou da casa dos mil, tendo então o Decreto representado apenas uma parte nesse processo. A maioria, estudantes das universidades federais: 71 expulsos na UFRJ; 34, na UFPE; 24, na UFMG; e 16, na UnB. Houve também expulsões em universidades particulares: três casos na PUC-RJ e quatro, na PUC-SP. As informações disponíveis sugerem ainda que a maioria das expulsões ocorreu entre 1969 e 1970, e que depois de 1974 não houve mais casos de aplicação do Decreto n.477 (p.160).

O expurgo de professores após o AI-5 veio completar a “Operação Limpeza" iniciada logo após o golpe. Estima-se que, em 1964, o expurgo atingiu aproximadamente cem professores, entre aposentados compulsoriamente e demitidos. Já em 1969, estima-se que esse número atingiu a casa dos 120 afastados (entre outras estimativas que giram em torno de 95 e 168 professores afastados) (p.164). A situação desses professores demitidos piorou com a decretação do Ato Complementar n.75 (AC-75), em 21 de outubro de 1969, que proibiu a atuação de todos os professores demitidos por razões “ideológicas” dentro do território nacional. Com isso, ficavam impedidos de assumir cargos em outras instituições de ensino e pesquisa públicos. O medo de punição, no entanto, atingiu também as instituições privadas, que evitavam contratar qualquer um que tivesse sido expurgado pelo AI-5 (p.173) - uma exceção, por exemplo, foi a PUC de São Paulo, que sob direção da arquidiocese da cidade, comandada por Dom Paulo Evaristo Arns, contratou inúmeros professores demitidos por razões políticas, como Florestan Fernandes e Octávio Ianni.

Por fim, o capítulo 5 tratará da organização do aparelho repressivo que atuaria dentro das instituições de ensino, destacando a criação das Assessorias Especiais de Segurança e Informações (Aesi ou ASIs), instaladas dentro dos cam- 
$p i$ universitários a fim de acompanhar de perto o desenrolar da vida acadêmica, e servir de braço do Sistema Nacional de Informação (Sisni), este que também já fora tema de trabalho anterior de Motta (2008). É fundamental compreender que a estrutura de funcionamento dos serviços de informação acompanhou a militarização do Estado brasileiro durante a ditadura militar. Com isso, o comando das operações na Divisão de Segurança e Informação do Ministério da Educação (cuja primeira sigla foi DSIEC, depois mudada para DSI/MEC) era de responsabilidade dos militares. Já o comando das Aesi dentro das universidades era dado a quadros da própria instituição, geralmente bacharéis em direito e/ou professores (Motta, 2008, p.38).

A criação do Serviço Nacional de Informação (SNI), em meados de 1964, teve como intenção atender as necessidades do regime militar em produzir informações de segurança e inteligência, especialmente contra os "inimigos internos”. Em 1967, foram reestruturados os serviços de informações do governo federal, através da ativação das Divisões de Segurança e Informações (DSI), que atuavam dentro dos ministérios civis. Por sua vez, as DSI foram criadas sob uma estrutura já existente, nas seções do Conselho de Segurança Nacional, também organizados nos ministérios. Em 1970, foram criadas então subdivisões do DSI, que seriam estabelecidas dentro de setores da sociedade controladas pelos ministérios, como empresas públicas, fundações e autarquias. Essas agências foram denominadas Assessorias de Segurança e Informação (ASI), ou Assessorias Especiais de Segurança e Informação (Aesi) (Motta, 2008, p.35). Dentro das universidades, a implementação das Aesi se deu a partir de 1971, quando o Ministério da Educação e Cultura (MEC) aprovou o Plano Setorial de Informações. A primeira delas seria instalada na UnB, em 19 de fevereiro de 1971, seguida da Aesi da Universidade Federal da Paraíba (UFPB), em março de 1971, e da Aesi da UFMG, em 16 de março de 1971. Na USP, a Aesi seria implantada em outubro de 1972 (Motta, 2008, p.35).

Ao mesmo tempo que punia, a ditadura militar reestruturava o ensino superior brasileiro, através de projetos de modernização, que serão analisados nos capítulos 2, 3 e 6 do presente trabalho. Transformações, no entanto, que não foram produtos diretos das políticas de Estado pós-1964. Desde a década anterior, era de comum acordo na sociedade brasileira em pleno desenvolvimento, entre os projetos da esquerda e da direita, que uma reforma universitária era fundamental, mesmo que ambos tivessem rumos específicos para a universidade. Para a esquerda, a universidade era um foco irradiador das transformações sociais e da superação das desigualdades dentro da sociedade brasileira. Queria-se, com isso, uma universidade aproximada das causas socialistas. Esse era o tom dos debates que tivera à frente a União Nacional dos Estudantes (UNE), a qual reivindicava também a mudança nas estruturas de poder dentro das universidades. Parte dessas reivindicações foi incorporada por João Goulart em sua proposta de "reformas de base", mas cujos planos não foram possíveis realizar devido ao golpe 
militar. Outro exemplo dos esforços, ainda no governo Goulart, pela reforma da educação, foram as criações da Universidade de Brasília (UnB) e do Instituto Tecnológico da Aeronáutica (ITA), ambas instituições fundadas sobre uma nova proposta estrutural e curricular. Já para a direita e os liberais de influência estadunidense, a universidade era também um foco fundamental para a continuidade do projeto de expansão da economia e da industrial nacional, sendo peça central na formação da mão de obra necessária para tal. Por fim, instaurado o regime militar a versão do bloco golpista seria a que daria rumo às reformas educacionais a partir de então.

No capítulo 2, serão analisados os projetos de modernização da educação superior tal qual proposta pelos militares. "Modernização", talvez o único aspecto progressivo, se bem que adotada por caminhos autoritários, de um grupo multifacetado da sociedade brasileira, que se uniu em torno daquilo que "não queriam", para usar a expressão de Motta: ou o "comunismo" e o governo Goulart. Projeto guiado pelos auspícios da política externa dos Estados Unidos para a América Latina na década de 1960, encabeçado por instituições privadas, como as Fundações Rockfeller e Ford e, em âmbito institucional, pela United States Agency for International Development (Usaid), criada pela administração J. F. Kennedy, em 1961, como ponta de lança da chamada "Aliança para o Progresso" (p.65).

No capítulo 3, será aprofundada a análise sobre os acordos entre o Ministério da Educação e a Usaid. A atuação da ICA/Usaid já se dava há mais de dez anos no Brasil, antes da instauração do regime militar. Pós-1964, porém, esses acordos foram estendidos devido à importância estratégica do ensino superior para o regime militar. No fim, os acordos não vingariam por conta dos desentendimentos entre o governo dos Estados Unidos e os militares no Brasil e os recursos financeiros destinados a apoiar projetos de desenvolvimento em diversas áreas foram diminuindo consideravelmente na década de 1970. Mesmo assim, os números revelam o grande interesse dos estadunidenses no processo de modernização do ensino superior, da pesquisa e da formação de mão de obra qualificada no Brasil (p.119).

O capítulo 6 tratará por fim dos resultados mais concretos do impulso modernizador da ditadura militar para a educação superior brasileira. Aqui, quatro pontos, em especial, devem ser destacados: 1) a mudança na carreira docente, com o fim do regime de cátedras e a reorganização das faculdades em departamentos, seguindo o modelo estadunidense. Com a extinção o regime de cátedras, foi possível começar a pensar na reestruturação da carreira docente, em especial com a proposta de implementação do modelo de Dedicação Exclusiva (DE), sugerida inicialmente em 1965, mas que só seria definitivamente regulada, com a definição das cargas horárias e salários, em 1970 (p.246); 2) houve ainda o aumento de vagas e expansão do ensino superior federal com o aumento dos recursos disponíveis, criando uma onda de federalizações de escolas privadas 
e institutos de pesquisa. Antes do golpe de 1964, segundo Motta, existiam 21 universidades federais e mais algumas faculdades federais isoladas. Em 1979, esse número subiu para 33 - aumento de $50 \%$ em uma década e meia (p.2478). Ocorreu também expansão no corpo docente: em 1968 os docentes federais somavam um total de 15 mil e em 1978 esse número chegou aos 38 mil - ou seja, um aumento de mais do que o dobro, em dez anos. Quanto ao número de estudantes matriculados, esse era de $100 \mathrm{mil} \mathrm{em} \mathrm{1968,} \mathrm{passando} \mathrm{para} 185 \mathrm{mil}$ em 1973 e saltando para 290 mil em 1979 (p.248); 3) houve ainda um aumento das verbas para a pesquisa, com a expansão da pós-graduação. Sua estrutura, tal qual proposta pelos militares, viria a tomar forma a partir de maio de 1964. A estrutura da pós-graduação no Brasil foi definida, no entanto, pelo "Parecer Sucupira" - estudo encomendado pelo MEC ao Conselho Federal de Educação e que levava o nome de seu autor, Newton Sucupira - apenas através da Lei de Reforma Universitária (n.5.540), em 1968. Nela se dividia a pós-graduação em strictu sensu e lato sensu, com a primeira correspondendo ao mestrado e ao doutorado e a segunda, à especialização, voltada para a formação de quadros profissionais aperfeiçoados (p.256). Houve ainda incremento dos programas de concessão de bolsas de estudo fora do país, permitindo que, na década de 1970, muitos estudantes optassem por cursar mestrado no país e o doutorado fora, com bolsa do governo. Com isso é possível afirmar que a expansão do ensino superior brasileiro, em todos os níveis, esteve atrelada à retomada do projeto desenvolvimentista dos primeiros anos da década de 1970 pelo regime militar. Os planos desenvolvimentistas, como o I PND (Plano Nacional de Desenvolvimento) e o II PND, incluíram em suas metas o incremento nas áreas de ciência e tecnologia, e no aumento de vagas e cursos na pós-graduação; e, por fim, 4) o aumento dos investimentos no crescimento da rede de ensino privado. Como também analisaram Demerval Saviani (2008) e Carlos Benedito Martins (2009), as políticas de expansão do ensino superior brasileiro nas propostas educacionais da ditadura militar tiveram papel decisivo na consolidação do ensino superior privado, baseado em uma "concepção produtivista" da educação, que adquiriu força impositiva ao ser incorporada na legislação do ensino durante o período militar, "na forma dos princípios da racionalidade, eficiência e produtividade". O que beneficiaria a parte do empresariado que havia composto o bloco golpista em 1964 e que exercia pressão direta nos órgãos reguladores da educação superior durante o regime militar.

O que havia no período pré-1964 era uma disputa entre projetos modernizadores. Com a vitória da coalização golpista em 1964, os militares tornaram-se então "agentes modernizadores", sem, com isso, e necessariamente, seguir o modelo que lhes haviam "sugerido" seus parceiros estadunidenses, "desdobrando em práticas repressivas mais drásticas" seu modelo de governo (p.11). Aqui, contudo, me parece haver um certo exagero na análise de Motta ao tentar diferenciar o autoritarismo de Estado brasileiro (especialmente nos anos de 1970, 
tal qual ele afirma na página 11) da influência estadunidense, está mais "liberal" e menos "repressiva", segundo sugere sua análise. É preciso lembrar que o próprio modelo repressivo desencadeado pelo Estado brasileiro teve influências diversas, entre elas dos próprios estadunidenses, que ajudaram na formação dos quadros que imporiam a tortura como prática comum nas locações policiais e militares estaduais e federais. A própria caça às bruxas dos comunistas, desencadeada pelo Estado brasileiro, inclusive nas universidades, teve inspiração direta no modelo praticado pelos Estados Unidos no imediato pós-guerra do período macarthista tanto quanto na tradição autoritária anticomunista da Era Vargas.

O que importa dizer, no entanto, e esse será o tema do capítulo 7 do presente trabalho, é que esse impulso modernizador do que poderíamos chamar de "ala liberal" do bloco golpista, e que sim, e por várias vezes, suplantou a pauta conservadora da ala mais à direita desse bloco, não se desfez do autoritarismo e repressão, se utilizando dos mecanismos do Estado para impor sua tecnocracia, como o caso da reforma universitária. Seria então um erro de interpretação diminuir os alcances do autoritarismo de Estado brasileiro no período da ditadura militar diante de sua face modernizadora, como Motta bem analisa no presente livro. "Modernizar" o país era parte do projeto autoritário daqueles que tomaram de assalto a república em 1964. Uma vez conquistado o poder, esse projeto poderia ser literalmente imposto, de cima para baixo, mesmo que, no caminho, houvesse a necessidade de pequenas concessões - como permitir que professores marxistas mantivessem seus cargos universitários desde que não fizessem proselitismo político em suas aulas - a fim de preservar quadros importantes entre os docentes.

Essa "acomodação das rivalidades", herança da cultura política brasileira desde a Era Vargas seria, por fim, o dínamo que resultaria na Lei da Anistia, sancionada em 28 de agosto de 1979 (Lei n.6.683), e cujos alcances Motta trata no capítulo 8, que fecha o livro. Um ponto importante a se considerar é que o processo de abertura, com gradual distensão política do aparelho autoritário, permitiu a acomodação dentro do novo contexto político daqueles que apoiaram o regime militar e de sua oposição. O que resulta em entraves - inclusive jurídicos - na revisão dos crimes cometidos pelo Estado brasileiro durante a ditadura militar, e a punição de seus agentes. Crimes pelos quais o Brasil já foi condenado na Corte Interamericana de Direitos Humanos, em dezembro de 2010, no "Caso Araguaia".

Retomar o debate sobre essas nuances políticas que cercaram as relações - ora liberais, ora conservadoras - do regime militar brasileiro com as universidades e suas comunidades nas décadas de 1960 e 1970 torna então a obra de Motta não apenas um libelo historiográfico no presente contexto político, social e econômico brasileiro, mas um exercício de memória coletiva de uma democracia que tenta, por fim, se consolidar definitivamente. Para isso, no entanto, para que se superem os entraves, por exemplo, no respeito institucional e coletivo aos 
direitos humanos e na construção de uma sociedade verdadeiramente inclusiva, as culpas, inclusive do Estado brasileiro, devem ser assumidas e erros dos anos de autoritarismo devem ser passados a limpo para que não se repitam.

\section{Notas}

1 Pode-se estimar um número de vinte a trinta mil presos no momento imediato ao golpe de 1964, a maioria deles solta após interrogatório. Em maio de 1964, estimava-se que algo entre três mil pessoas ainda permaneciam presas (p.26).

2 Uma boa parte desse acervo já digitalizada e aberta a consulta pública pode ser encontrada no portal "Armazém memória". Disponível em: <http://www.armazemmemoria.com.br/Centros.aspx?id=2>.

\section{Referências}

MARTINS, C. B. A reforma universitária de 1968 e a abertura para o ensino superior privado no Brasil. Educ. Soc., Campinas, v.30, n.106, p.15-35, jan./abr. 2009. Disponível em: <http://www.cedes.unicamp.br>.

MOTTA, R. P. S. Em guarda contra o perigo vermelho. O anticomunismo no Brasil. São Paulo: Perspectiva/Fapesp, 2002.

Os olhos do regime militar brasileiro nos campi. As assessorias de segurança e informações nas universidades. Topoi, v.9, n.16, p.30-67, jan.-jun. 2008.

. As universidades e o regime militar. Rio de Janeiro: Zahar, 2014.

SAVIANI, D. O legado educacional do Regime Militar. Caderno Cedes, Campinas, v.28, n.76, p.291-312, set./dez. 2008. Disponível em: <http://www.cedes.unicamp.br>.

Matheus Cardoso da Silva é historiador; doutorando no Departamento de História da Universidade de São Paulo, bolsista da Capes. @ - stardus_mat@yahoo.com.br

Recebido em 24.11.2014 e aceito em 15.12.2014.

${ }^{\text {I }}$ Faculdade de Filosofia, Letras e Ciências Humanas, Universidade de São Paulo, São Paulo/São Paulo, Brasil. 
